\title{
The Steering of a Satellite by Ion Propulsion
}

\author{
R. Fox
}

\section{DISCLAIMER}

This report was prepared as an account of work sponsored by an agency of the United States Government. Neither the United States Gnvernment nor any agency thereof, nor any of their empleyees, makes any warranty, express or implied, or assumes any legal liability or responsibility for the accuracy, completeness, or usefulness of any information, apparatus, product, or process disclosed, or represents that its use would not infringe privately owned rights. Reference herein to any specific commercial product, process, or service by trade name, trademark, manufacturer, or otherwise does not necessarily constitute or imply its endorsement, recommendation, or favoring by the United States Government or any agency thereof. The views and opinions of authors expressed berein do not necessarily state or reflect those of the United States Government or any agency thereof.

\section{EIVED

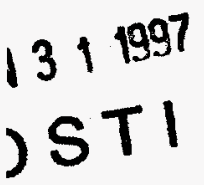

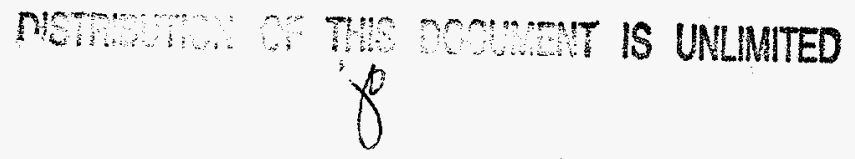

June 18, 1958

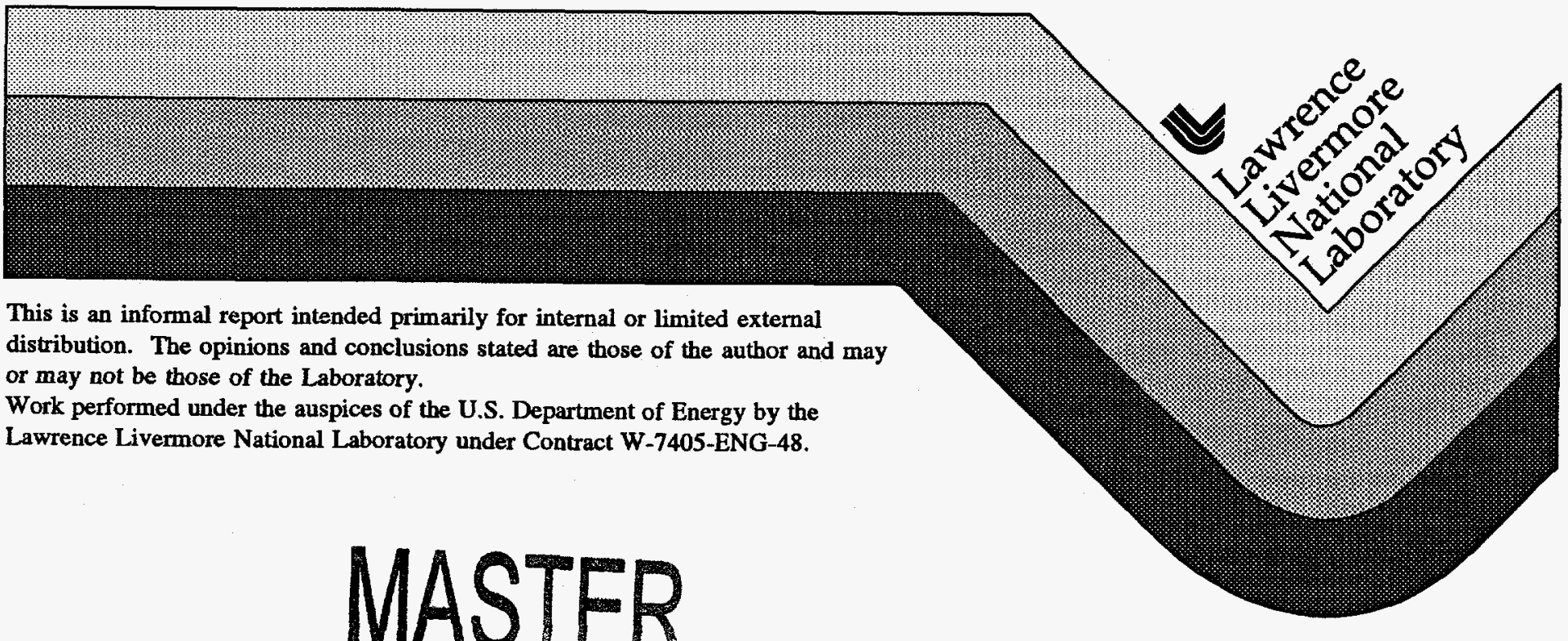




\section{DISCLAMMER}

Portions of this document may be illegible in electronic image products. Images are produced from the best available original document. 
SUBJECT CLASSIFTCATION:

"Ion Rocket"

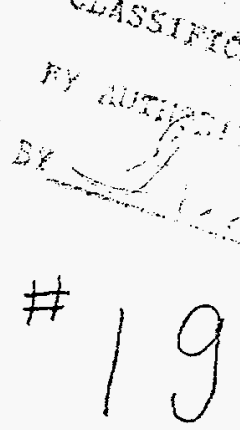

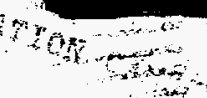

This document consjst of

2. of
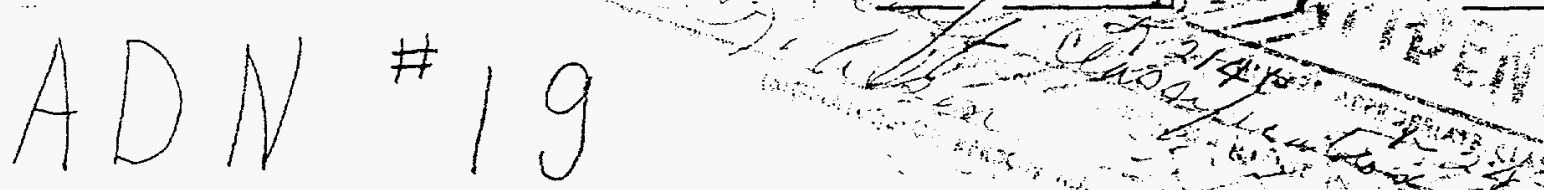

MEMORANDUM - June 18,1958

TO: Distribution

FROM: $\quad$ Robert Fox

SUBJECT: ADN NO.19: THE STERRRING OF A SAMELITLE BY ION PROPULSION

ADVATCED DEVELOPMENI NOTE NUMBER NINHEIEFN

I. INIRODUCTION:

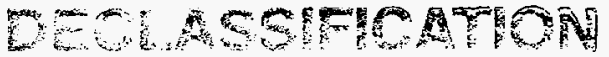

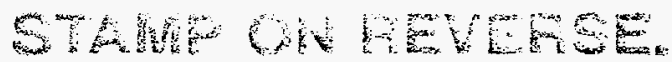

One of the possible military applications for an Ion propulsion system is the steering of reconnaisance satellites for extended periods of time. Two reasons for doing this are immediately apparent. First, the orbit could be perturbed in a random pre-programmed manner. Such pertur-

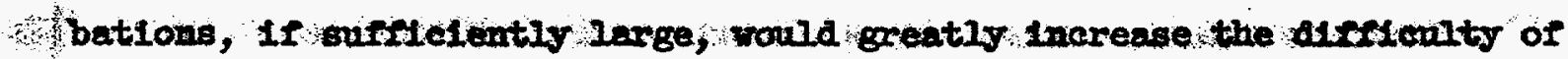
interception and destruction of the vehicle. Second, if the orbit could be made to rotate contimuously in space at a rate of one revolution per day then a single vehicle could keep under surveillance a given area of interest. This turns out to be a much more difficult requirement in terms of required ion rocket performance than does the Ilrst requirement.

II. ORBIT DYNAMICS:

Consider now the perturbation problem. In order to define the problem we assume that the earth is spherical and that the satellite orbit is inftially circular with an altitude of about 200 miles. Further, assume constant thrust per unit mass is applied by the propulsion system. Assume that at time $t=0$ (and earlier times) the enemy makes the necessary obcervations for detormining the orbit parameters and plans to atteupt an Intercept one period later $\left(t=\tau_{0}\right)$. The problem is now to introduce a

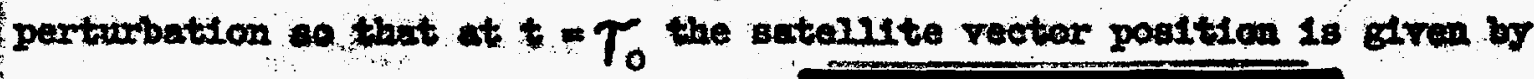

$$
\underline{r}\left(\tau_{0}\right)=\underline{r}_{0}\left(\tau_{0}\right)+\underline{\Delta r}
$$


$r_{0}\left(\eta_{0}\right)$ is the unperturbed position at $t=\tau_{0}$. We now consider seperately three distinct modes of application of the thrust vector:

1. Perpendicular to the orbital plane (transverse thrust)

2. Parallel to the orbital plane and perpendicular to the radius vector from the center of the earth (circumferential thrust)

3. Parallel to both the orbital plane and radius vector (radial thrust)

These three cases are shown schematically in Figures 1, 2, 3. Solution is achieved by an approximate method which assumes that the perturbations are small.

Consider flrst the case of transverse thrust. The equation for the vector $\underline{h}$ representing the angular momentum per unit mass is

$$
\underline{\dot{\hat{n}}}=\underline{\underline{r}} \times \underline{\underline{I}} \quad \rho=\text { force per unit mass }
$$

In component form,

$$
\begin{aligned}
& \dot{h}_{x}=\operatorname{Ir} \sin \theta \\
& \dot{h}_{y}=r \cos \theta
\end{aligned}
$$

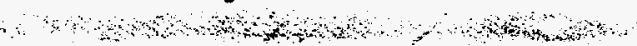

For on observer at $x=r_{0}, y=z=0$, variations in $h$ result in tilting of the orbit about the $y$ - axis and hence a miss distance after one revolution

$$
\frac{\Delta z}{r_{0}}=\frac{\Delta h_{x}}{h_{0}} .
$$

Variations in $h_{y}$ result in a tilting about the $x$ - axis and hence a miss distance of zero. Only the direction of approach of the satellite to the interception point is perturbed and the perturbation is

$$
\Delta \phi=\frac{\Delta h_{y}}{h_{0}} \text {. }
$$

as we shall see, the latter effect is certainly insigniflcant.

The projection of $\underline{h}$ in the $x, y$ plane for constant positive $I$ is shown in Figure 4 (a). If $I$ is made negative for $\pi<\theta<2 \pi$, the result 18 ahow in Flgure 4 (b). Clearly, this mode of eperation gives maximm $\Delta \mathrm{h}_{\mathrm{x}} /$ turn.

We have for one revolution,

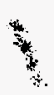




$$
\begin{array}{rlr}
\Delta h_{x} & =f r \gamma_{0} \overline{\sin \theta} \quad 0<\theta<\pi \\
& =\frac{2}{\pi} \operatorname{sr} \tau_{0} .
\end{array}
$$

Therefore, since $r(t) \simeq r_{0}(0)$,

$$
\frac{\Delta z}{r_{0}}=\frac{\Delta h_{x}}{h_{0}}=\frac{2}{\pi} \frac{f r_{0} \gamma_{0}}{r_{0} v_{0}}=4 f / g_{0} .
$$

$g_{0}=$ gravitational attraction at $r=r_{0}$

Now consider the case of circumferential thrust. Since the thrust is applied parallel to the velocity vector a mall change in orbit energy w111 oceur, appreciable changes in both $\tau, x\left(\tau_{0}\right)$ wi11 occur. From the angular momentum equation we have,

$$
\begin{aligned}
& \dot{h}=\operatorname{Ir} \\
& \text { so } \\
& h(t)=h_{0}+\operatorname{srt}
\end{aligned}
$$

We can estimate the time $T$ required for one revolution as follows:

$$
T=\pi(t) \text { where } \tau=\text { Instantwheous period }
$$

Now

$$
\frac{\tau}{\tau}=\frac{\mathrm{h}^{3}}{\mathrm{~h}_{0}^{3}}
$$

Therefore from (8), (9)

$$
\frac{\bar{\tau}(t)}{\tau_{0}}=\frac{1}{\tau_{0}^{h_{0}^{3}}} \int_{0}^{\tau_{0}} h^{3}(t) a t \simeq 1+3 / 2 \frac{\operatorname{er} \tau_{0}}{h_{0}}=1+3 \pi f / g_{0}
$$

Thus

$$
\frac{T-\tau_{0}}{\tau_{0}}=3 \pi \mathrm{I} / \mathrm{s}_{0}
$$

The corresponding position perturbation is

$$
\frac{\Delta y}{r_{0}}=2 \pi \frac{\left(T-T_{0}\right)}{T_{0}}=6 x^{2}+/ s_{0}
$$


The instantaneous period is

$$
\frac{\tau\left(\tau_{0}\right)}{\tau_{0}}=\frac{h^{3}\left(\tau_{0}\right)}{h_{0}^{3}}=\left(\frac{r}{r_{0}}\right)^{3 / 2}
$$

Therefore

$$
\frac{\Delta r}{r_{0}}=\frac{2 r r_{0} \tau_{0}}{h_{0}}=4 \pi \mathrm{r} / \mathrm{g}_{0}
$$

F'nally, we consider the case of radial thrust. H.S. Tsien (1) has given an exact integral for the equation of motion in the form

$$
t=\frac{\tau_{0}}{2 \pi} \int_{0}^{p} \frac{d p}{\sqrt{(p-1)\left(2 \mu p^{2}-p+1\right)}}, p=\frac{r}{r_{0}}, \mu=f / g_{0}
$$

Let

$$
p=1+\delta
$$

and assume

$$
\delta<<1 .
$$

Then, to lst order the integral is

$$
\frac{\pi(1+\mu)}{2 \sqrt{1-2 \mu}}-\sqrt{(2 \mu-\delta)}+\frac{(1+\mu)}{\sqrt{1-2 \mu}} \sin -1\left[\left(\frac{\delta}{\mu}-1\right)-2 \delta\right] \text {. }
$$

After one period $t \simeq \tau_{0}$ this expression must have the value $2 \pi$. For $\mu<<1$ this can only be the case if

$$
\frac{\Delta r}{r_{0}}=\delta<<\mu=I / s_{0}
$$

In fact, even after a very long time $t>>\tau_{0}$, we find that the satellite reaches an equilibrium orbit characterlzed by the force equilibrium

$$
g_{0}\left(\frac{r_{0}}{r}\right)^{2}=r+\frac{v^{2}}{r}
$$

a.so,

$$
V r=v_{0} r_{0} \quad \text { since } h=\text { constant }(\underline{I} \times \underline{r}=0) .
$$

The resulting displacenent is:

$$
\left(\frac{\Delta r}{x_{0}}\right) \simeq I / g_{0}
$$

Consequently, radial thrust is of no interest. 
Let us now summarize the results for the orbit perturbation achieved after one turn by the various modes of applying thrust. In order to illustrate the magnitudes: involved, values are calculated for $f=0.2 \mathrm{~cm} / \mathrm{sec}^{2}$ and $r_{0}=4200$ miles.

$$
\begin{aligned}
& \text { Mode of applying } \\
& \text { thrust }
\end{aligned}
$$

Circumferential

\section{Displacement after one revolution}

$$
\begin{aligned}
& \frac{\Delta y}{r_{0}}=6 \pi^{2} \mathrm{f} / \mathrm{g}_{0} \\
& \frac{\Delta \mathrm{r}}{r_{0}}=4 \pi \mathrm{r} / \mathrm{g}_{0}
\end{aligned}
$$

\section{Transverse}

$\left(\begin{array}{c}\text { thrust reversal at } \\ \theta=0, \pi\end{array}\right)$

$\left(\begin{array}{c}\text { thrust reversal at } \\ \theta=\pi / 2,3 \pi / 2\end{array}\right)$$$
=0.46^{\circ}
$$

Radial

$$
\frac{\Delta z}{r_{0}}=4 \mathrm{f} / \mathrm{g}_{0}
$$$$
\Delta \phi=4 \mathrm{r} / \mathrm{g}_{0}
$$

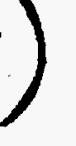

$\Delta \varphi=41 / 8_{0}$

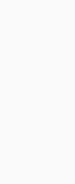

$\frac{\Delta r}{r}<<18$

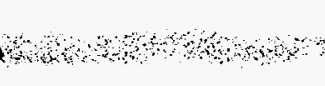

III. CHARACPERISTICS OF THE ION PROPULSION SYSTTEM:

Now it is necessary to relate these results to the specific power capebilities of an ion rocket. In this way we can assess the technological feasibility of steerable satellites. It bas been shown. (2) that the following relation exists for an lon rocket:

$$
\begin{aligned}
& \tau_{a} \geqslant \frac{(\Delta V)^{2} \text { eff }}{2 K} \frac{\mu(I+\delta)}{(\mu-I)} \\
& \tau_{a}=\text { total acceleration time } \\
& \mathrm{K}==\text { specific power, } \frac{\text { exhaust power }}{\mathrm{t}} \\
& \text { totel propulsion plent mass } \\
& (\Delta v) \text { ert }=\text { effective relocity change }=I \tau_{a}
\end{aligned}
$$

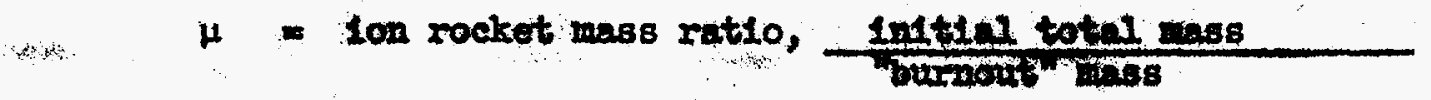

$$
\begin{aligned}
& \delta=\text { Deriaad mass } \\
& \text { propulsion equipment mass }
\end{aligned}
$$




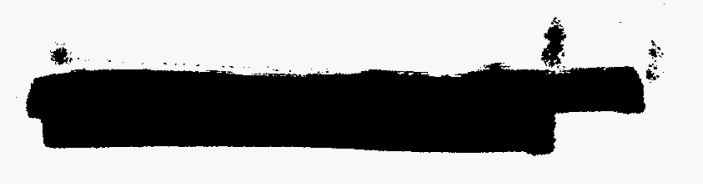

The equality sign applies for the "optimum" exhaust velocity program

$$
v_{\text {ex }}(t)=\frac{(\Delta V) \text { eff }}{\mu-I} \frac{M_{\text {initial }}}{M_{\text {initial }}-m(t)}
$$

$$
\mathrm{m}(\mathrm{t})=\text { propellant consumed in time interval } 0<t^{\prime}<t^{\prime}
$$

Since $(\Delta V)$ eff $= \pm \gamma_{a}$,

$$
\tau_{\mathrm{a}} \leq \frac{2 \mathrm{~K}}{\rho^{2}} \frac{\mu-1}{\mu(1+\delta)}
$$

This expression relates the "lifetime" $\mathcal{T}_{a}$ to the system parameters. Note that

$$
\frac{\text { payload mass }}{\text { initial total mass }}=\frac{\delta}{p-(1+\delta)}=\mathrm{h}
$$

Thus, (22) becomes

$$
\gamma_{a} \leq \frac{2 K}{r^{2}} \frac{(\mu-1)(1-h \mu)}{\mu}
$$

If we want to maximize the lifetime $\gamma_{\text {a }}$ subject to the requirement that $\mathrm{h}$, the ratio of payload mass to initial mass is fixed, then we must have

$$
\mu_{\text {opt }}^{2}=1 / n
$$

so

$$
\tau_{a} \leq \frac{2 k}{f^{2}} h\left(\sqrt{\frac{1}{b}}-1\right)^{2}
$$

We may now combine (12), (24) in order to relate lifetime, specific power, and payload. We have:

$$
\tau_{a} \leqslant 72 \pi^{4} K\left(\frac{r_{0}}{\Delta y r_{0}}\right)^{2} h\left(\sqrt{\frac{I}{b}}-1\right)^{2}
$$

Results are given in Figure 5 for $h=0$ (no payload), $r_{0}=4200$ miles. The dependence of $\tau$ apon the payload term is shown in Figure 6. We see that the lifetime is strongly dependent on the payload fraction $h$ when $K, \Delta y$ are IIxed. One could alternatively inquire about the sensitivity of $\Delta y$ to the payload when $\tau_{a}$, $K$ are Iixed. The result is shown in Figure 7. Clearly,

$$
\frac{\Delta y}{(\Delta y)_{h=0}}=\sqrt{\frac{T_{a}}{\left(T_{h=0}\right)_{h}}}
$$


IV. CONCLUDING REMARKS

The effect of an orbit perturbation upon the interception probability depends upon the detailed nature of the observation system used for obtaining orbit parameters and the intercept vehicle performance. Suppose final fixes can be made when the satellite first passes over the boundary of a country and utilized for final adjustment of firing time and orientation of the intercept vehicle within the next few minutes. In this case, perturbations like $50 \mathrm{mlles}$ per turn are probably not very significant. If firing times mast be computed from the previous pass mast be used, then a significant reduction in intercept probability may result unless the terminal guidance capabilities are considerably augmented. Note that a 50 mile perturbation corresponds to an angular deviation of about $15^{\circ}$ as seen from the earth's surface (200 mile orbit). It is clear that perturbations like several hundred miles per turn together with reasonable propulsion system lifetime cannot be achieved without a specific power considerably in excess of $0.1 \mathrm{k} \mathrm{w} / \mathrm{kg}$.

REFERENCES

(1) H. S. Tsien, "Iake-off From Satellite Orbit", Journal of the Americen Rocket Society", 23, 233, July - August 1953.

(2) R. H. Fox, ("The Payload Capabilities of Ion Propulsion Rocket System") UCRI - 5199. (to be issued)

DISTRTBUIION
1. H. Brown
2. R. Finke
3. R. Fox
4. E. Goldberg
5. H. Gordon
6. J. Hadley
7. A. Matmont
8. R. Meuser
9. R. Measerer
10. T. Merkle
11. H. Reymolas
12. J. Ruff

13. E. Teller

14. T. Merkle/File

15. T. Merkle/File

16. T. Merkle/File

17. R. Stuart

18. Commander Michael Moore 
Page 8

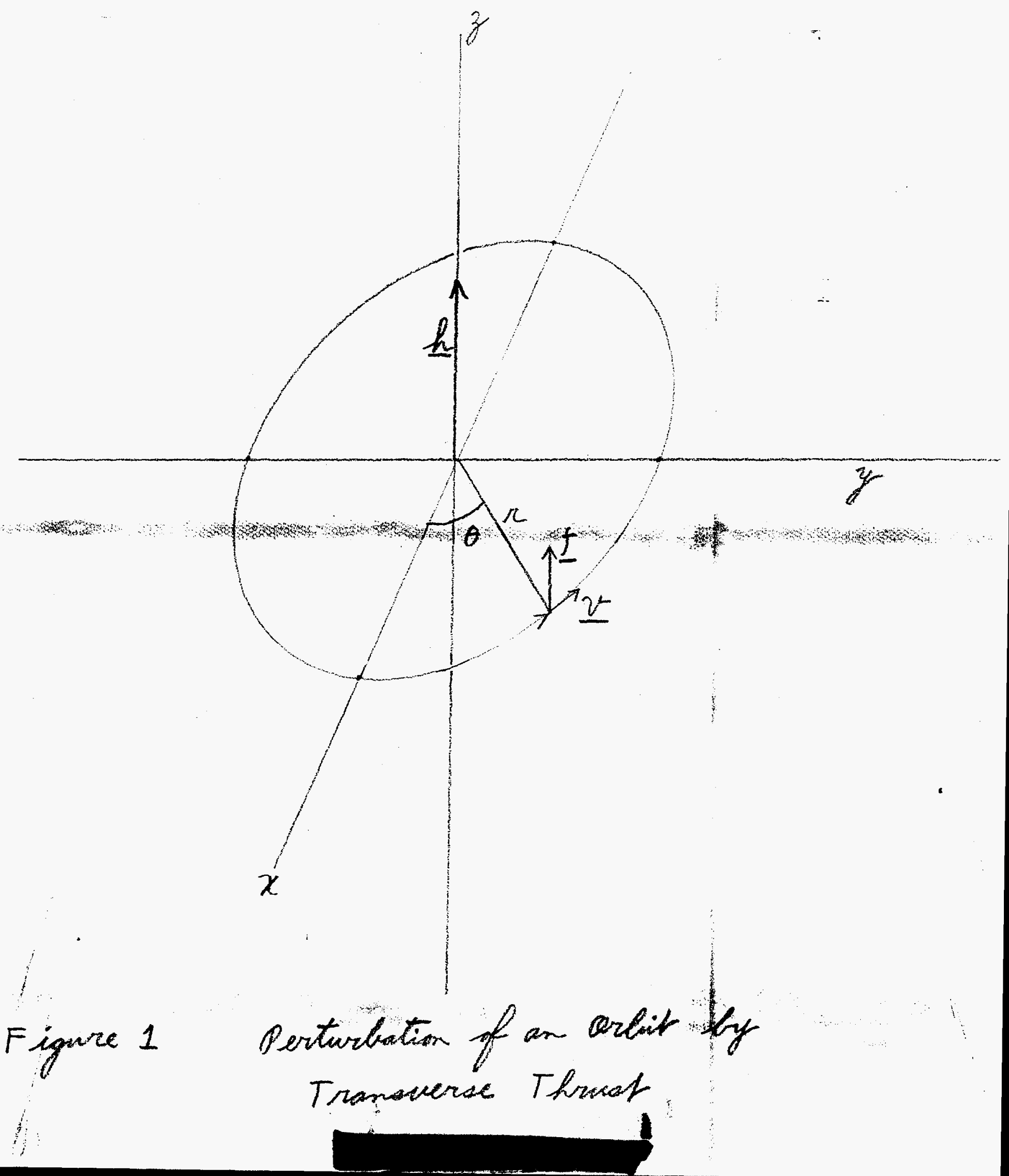


Page 9

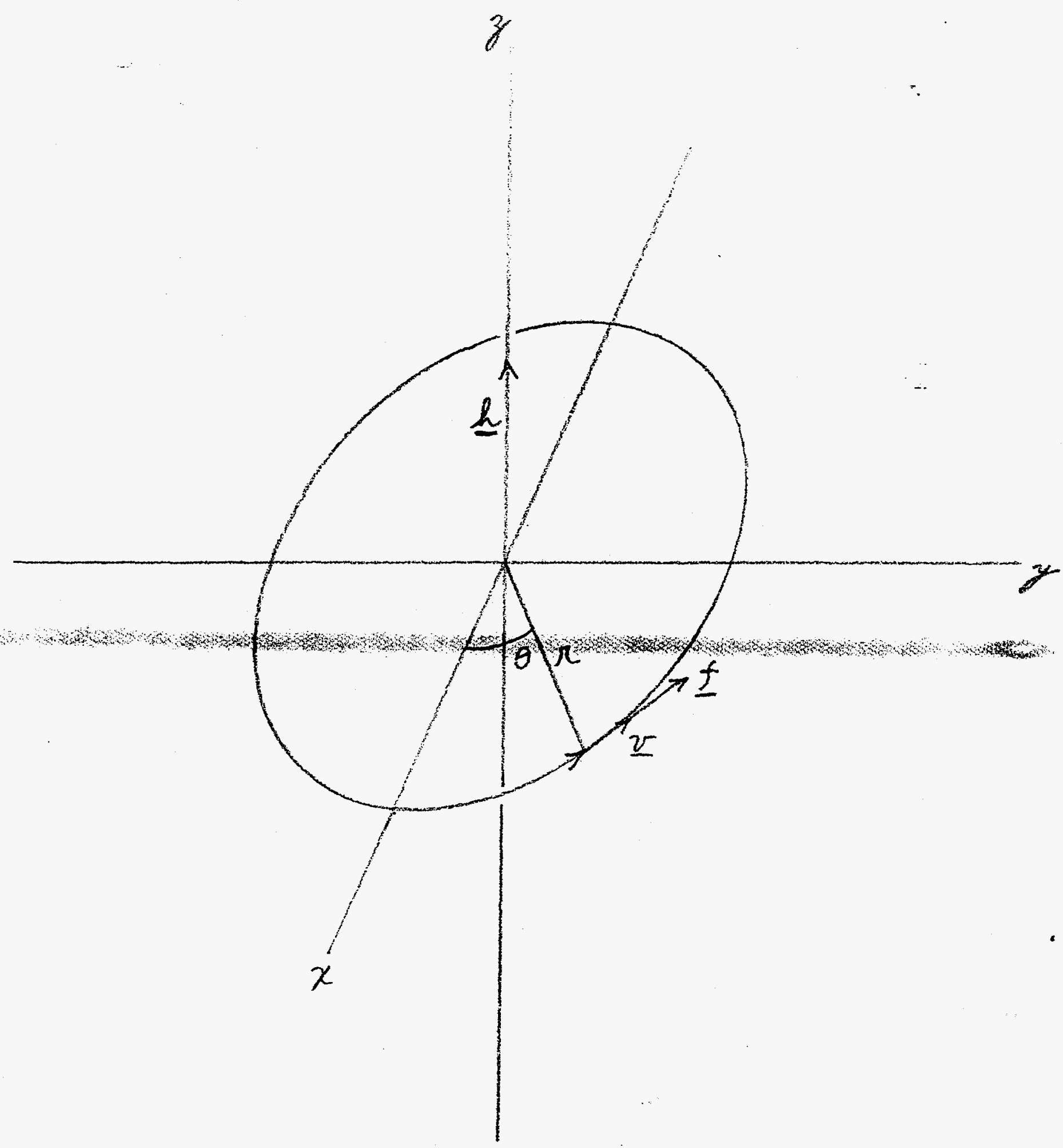

Figure 2 pertablation of an arbit by Circumfermantial Thuset 


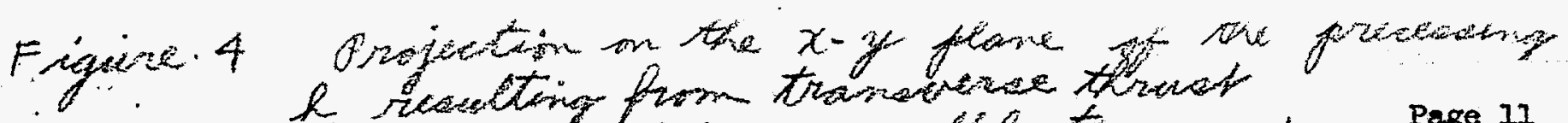

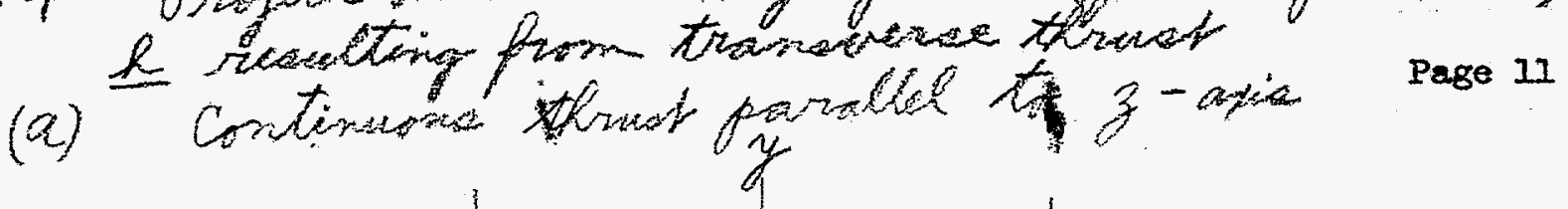

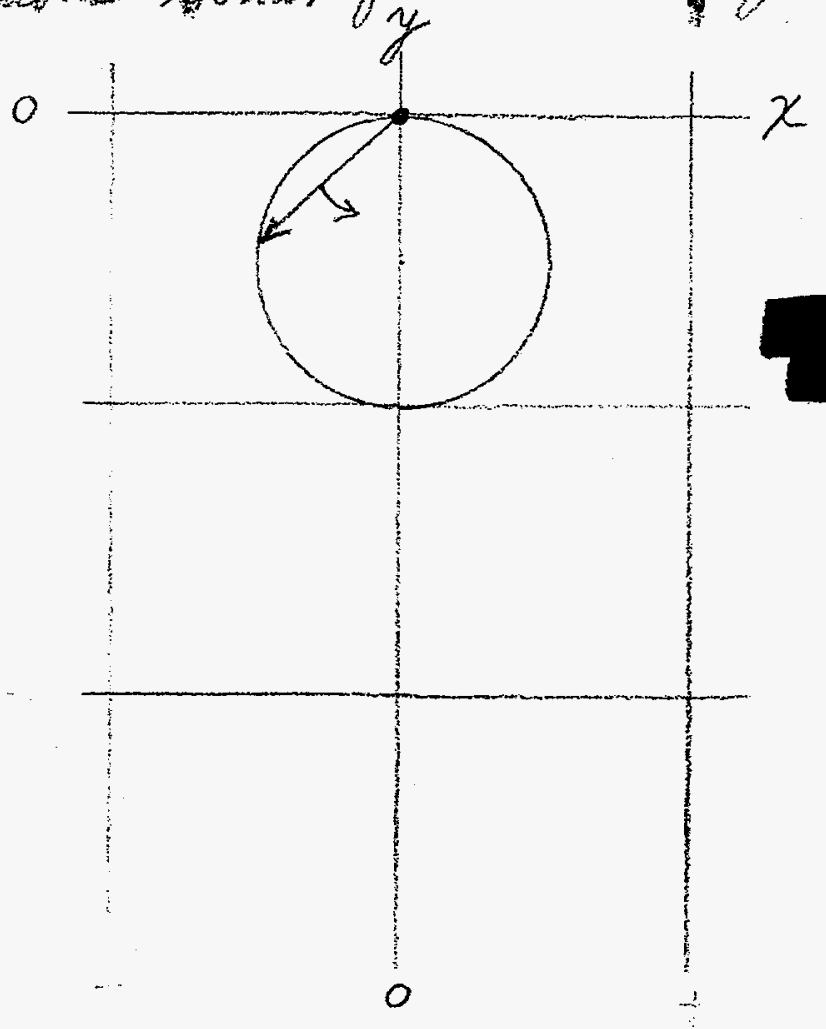

(b) Thust reverad anh $\pi<\theta<2 \pi$

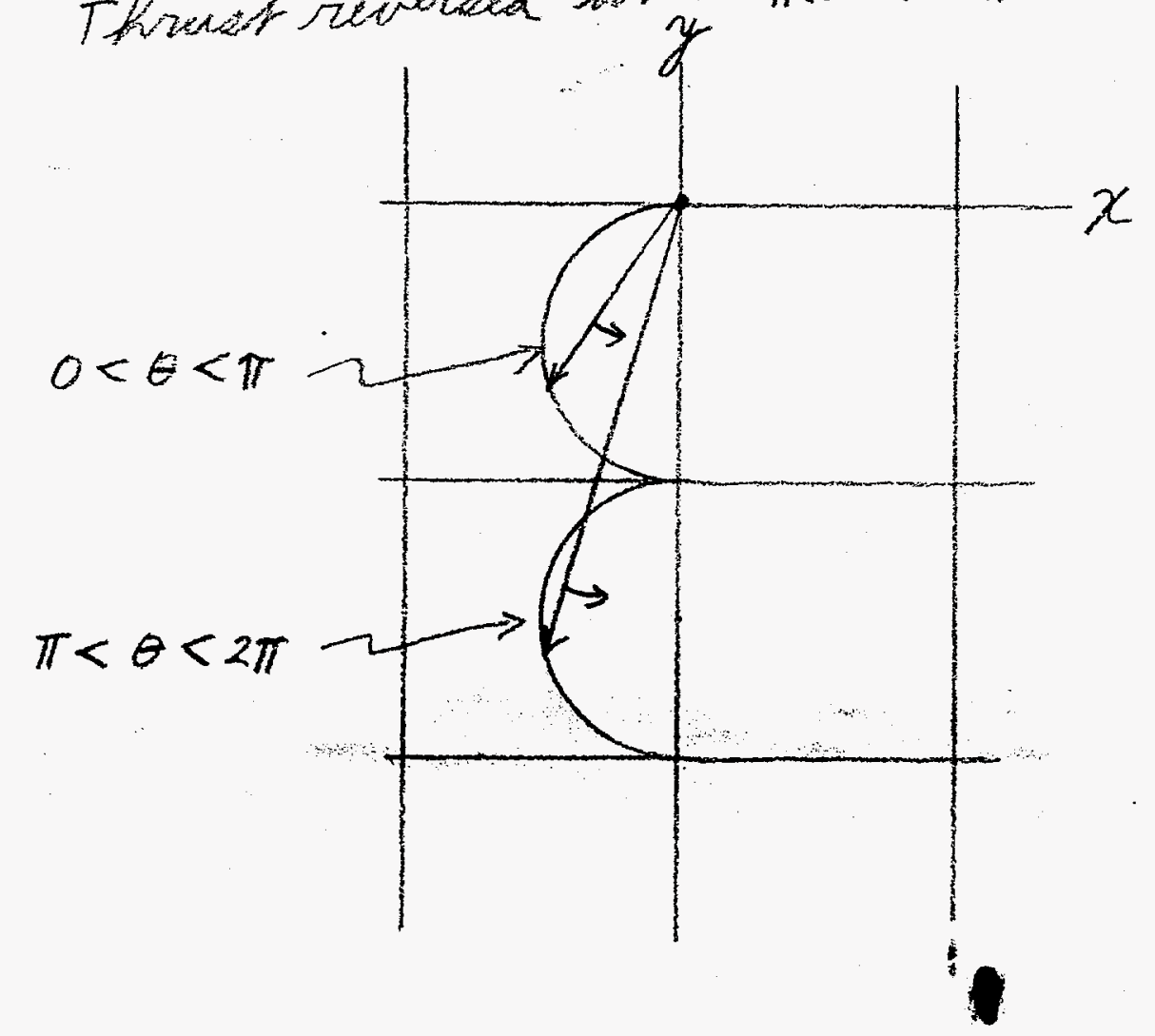




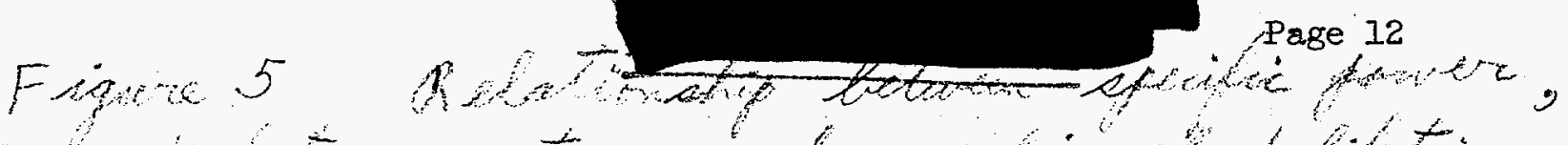

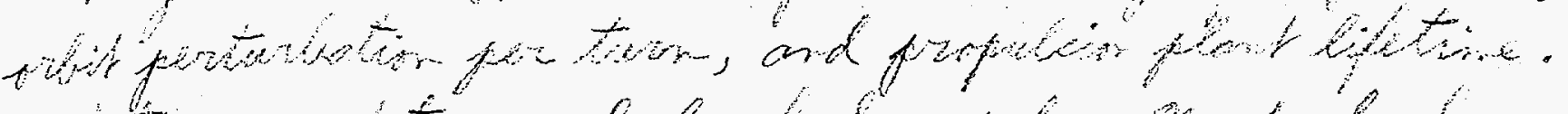

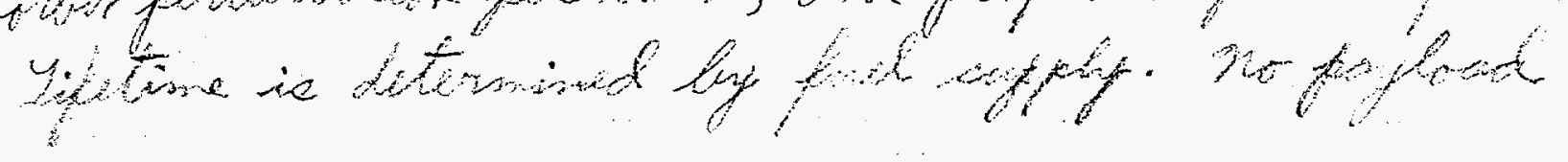

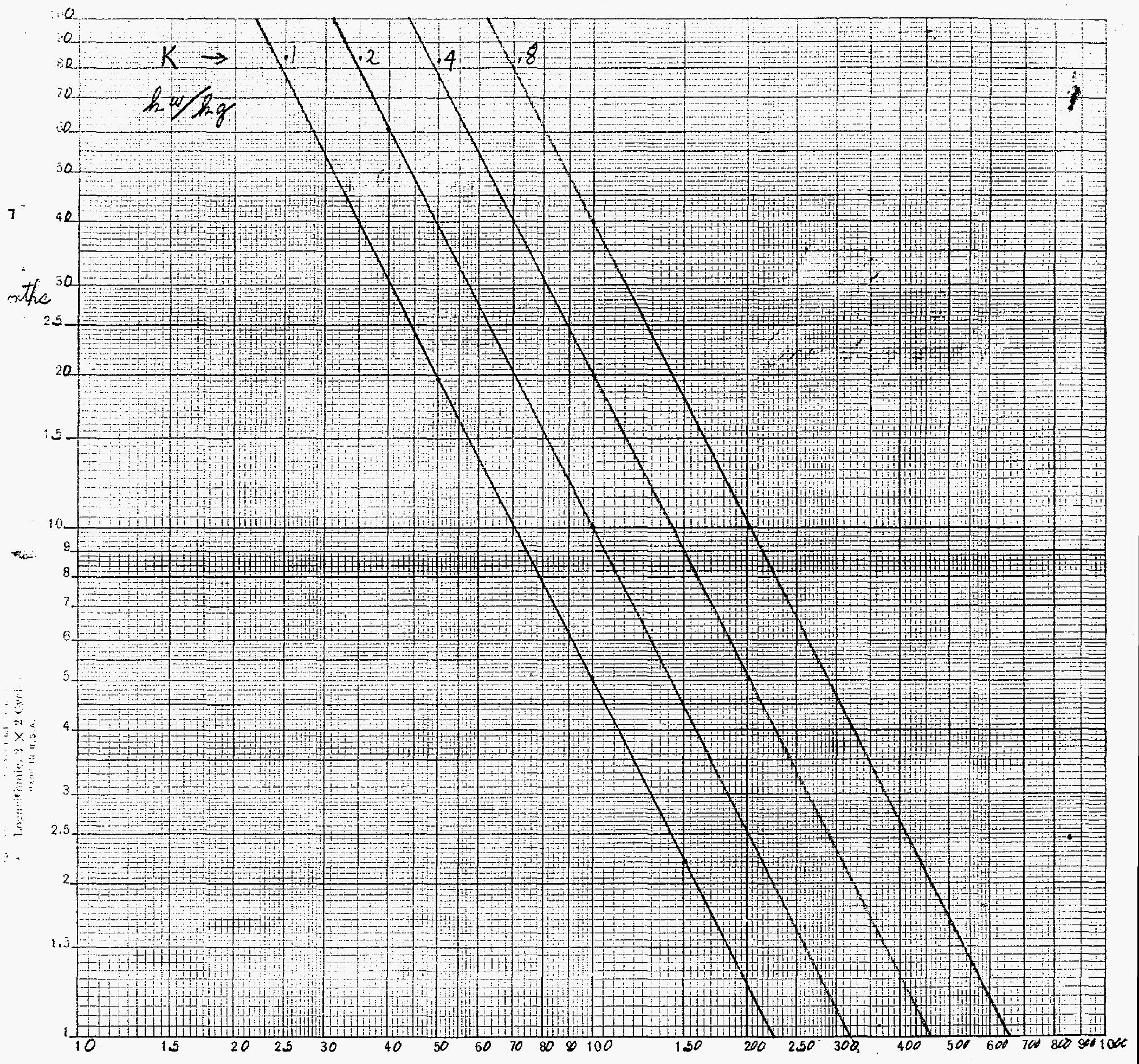

$(\Delta y)_{\text {twr }} \quad$ miles 
